\title{
Cutaneous Low-Dose Radiation Increases Tissue Vascularity through Upregulation of Angiogenic and Vasculogenic Pathways
}

\author{
Vishal D. Thanik ${ }^{a} \quad$ Christopher C. Chang $^{a}$ Oren Z. Lerman ${ }^{a}$ Matthew R. Greives ${ }^{a}$ \\ Huong Le ${ }^{a}$ Stephen M. Warren ${ }^{a}$ Robert J. Schneider ${ }^{a}$ Sylvia C. Formenti ${ }^{b}$ \\ Pierre B. Saadeh ${ }^{a}$ Jamie P. Levine ${ }^{a}$ \\ anstitute of Reconstructive Plastic Surgery Laboratories and ' ${ }^{\mathrm{b}}$ Department of Radiation Oncology, \\ New York University School of Medicine, New York, N.Y., USA
}

\section{Key Words}

Radiation • Angiogenesis • Vasculogenesis •

Neovascularization

\begin{abstract}
Background/Aims: Neovascularization involves angiogenesis and vasculogenesis mediated by cytokines and soluble chemokines. The predominant stimulus is ischemia, however, recent data suggest that ionizing radiation (IR) has angiogenic potential. In this study we evaluated whether IR increases vascularity and perfusion in vivo. Methods: In wildtype mice, a full-thickness, pedicled skin flap was created and isolated for localized irradiation at a dose of $5 \mathrm{~Gy}$. Serial Doppler analysis of the flap was performed. The skin flaps were then harvested at various time points for vascularity and histologic analysis. Blood was concurrently harvested for serum and hematopoietic progenitor cell population analysis. Results: IR to an ischemic flap augmented the angiogenic cytokines SDF-1 and VEGF. Serum MMP-9 and s-kit levels, which are critical for progenitor cell mobilization, were also increased. When hematopoietic progenitor cells were evaluated by Sca1+/Flk1+ cells, a correlate 2 -fold increase was seen compared to controls. When the flaps were examined, both vascularity and perfusion were increased. Conclusion: In this study we demonstrate that local, low-
\end{abstract}

\section{KARGER}

Fax +41613061234 E-Mail karger@karger.ch www.karger.com (c) 2010 S. Karger AG, Base

$1018-1172 / 10 / 0476-0472 \$ 26.00 / 0$

Accessible online at:

www.karger.com/jvr dose IR upregulates angiogenic chemokines and results in progenitor cell mobilization to the systemic circulation. There is a resultant increase in the vascularity of the irradiated flap, suggesting that the pro-angiogenic effects of IR can be harnessed locally.

Copyright $\odot 2010$ S. Karger AG, Basel

\section{Introduction}

Neovascularization after ischemic injury is a multifactorial process, involving angiogenesis and vasculogenesis mediated through the elaboration of hematopoietic cytokines and soluble chemokines. These factors are regulated predominantly through the hypoxia-inducible factor-1 (HIF-1) axis. Through this master regulator, cytokines such as vascular endothelial growth factor (VEGF), placental growth factor (PlGF) and stromal cell-derived factor-1 (SDF-1) promote new blood vessel growth [1-4]. SDF-1 has been demonstrated to be a key regulator in vasculogenesis by recruitment of endothelial progenitor cells (EPCs) and hemangiocytes through interaction with its receptor, CXCR4 [5-7].

While the predominant stimulus for cytokine-mediated angiogenesis and vasculogenesis is ischemia, recent data suggest that ionizing radiation (IR) alone has angio-

Dr. Jamie P. Levine

Institute of Reconstructive Plastic Surgery

New York University School of Medicine

560 First Avenue, TH-169, New York, NY 10016 (USA)

Tel. +1 212263 1062, Fax +1 212263 8492,E-Mail jamie.levine@ nyumc.org 
genic potential $[8,9]$. In in vitro models, IR has been demonstrated to directly induce HIF-1 activity [8], as well as upregulating HIF-1 induced cytokines VEGF and SDF-1 through HIF-1-dependent and HIF-1-independent pathways [unpubl. data]. Furthermore, in vivo studies have demonstrated that IR directly upregulates matrix metalloproteinase-9 (MMP-9), which is known to mobilize EPCs from the bone marrow cavity [9]. These combined stimuli have been shown to potentiate the hypoxic response.

In the clinical setting, the response to ischemic injury is often suboptimal, with inability to generate a sufficient angiogenic response to reverse ischemia. The resultant effects of hypoperfusion, cell death and tissue damage are well described. The ability to augment this response has significant therapeutic implications. Based on these recent reports of the angiogenic potential of IR, we hypothesized that the controlled addition of IR to an ischemic full-thickness cutaneous flap could improve the host vascular response to ischemic injury.

In this study we show that targeted, nonsystemic ionizing radiation delivered to a dorsally based skin flap initiates systemic upregulation of angiogenic and vasculogenic chemokines, suggesting that small doses of irradiation in a limited field create a stimulus for systemic response. Furthermore, this signaling triggers a cascade of events that results in increased progenitor cell mobilization from the bone marrow compartment into the systemic circulation. Most importantly, we find a resultant increase in the vascularity of the irradiated flap. Our results suggest that the pro-angiogenic effects of IR can be harnessed without the known negative effects of radiation therapy by dose-field limitation and dose modulation.

\section{Materials and Methods}

\section{Mouse Model}

All experiments were performed in accordance with New York University Animal Care and Use Committee guidelines. Eight- to ten-week-old male wild-type FVB mice $(\mathrm{n}=50)$ or tie $2 / \mathrm{LacZ}$ transgenic mice $(n=18)$, which incorporate the lac $Z$ gene driven by the endothelial-specific tie 2 promoter (Jackson Laboratories), were anesthetized using a mixture of ketamine, xylazine and acepromazine. Hair was removed from the dorsal skin using an electric clipper and depilatory agent (Nair). A full-thickness pedicled skin flap [10] was created, elevated and isolated for localized radiation. Following treatment, the skin was re-opposed and incisions were closed with 6-0 nylon suture (Ethicon). The wound was dressed with Bacitracin ointment and Tegaderm to prevent infection and dehiscence (fig. 1).

Cutaneous Radiation Increases Tissue Vascularity

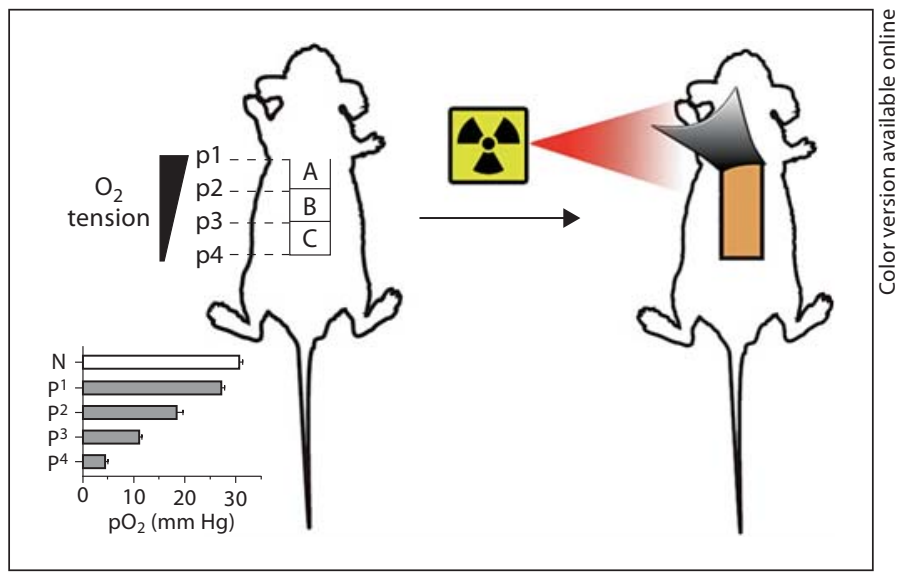

Fig. 1. Murine model of isolated, cutaneous radiation to an ischemic flap. A full-thickness pedicled skin flap is created, resulting in graded ischemia to the flap. It is then elevated and radiation is selectively delivered to the flap. Ischemic tissue is then harvested for gross, microscopic, cellular and molecular assays. Whole blood and bone marrow are collected to measure systemic response.

\section{Radiation}

Mice were laid longitudinally and the flaps secured with Tegaderm. Lead shields were placed to protect the head, body, spine and tail of the animal, while exposing the elevated flap to the radiation field. Treated animals were exposed to 5 Gy XRT using a Varian 2300 Linear Accelerator. The dose energy was $6 \mathrm{MeV}$, with a dose rate of 1,000 CGy/min. Field size was a $20 \times 20 \mathrm{~cm}$ electron cone, with the source to skin distance being $100 \mathrm{~cm}$ to the top of the $1-\mathrm{cm}$ bolus. Control animals had their flaps secured in an identical fashion for an equal amount of time, but were not radiated.

\section{Skin Perfusion Analysis}

A laser Doppler perfusion image analyzer (Moor Instruments) recorded blood flow in the flap, utilizing previously described methods [11]. Briefly, the instrument generates a 2-mW heliumneon laser that sequentially scans the tissue surface at a depth of $600 \mu \mathrm{m}$. The blood cells moving through the vasculature shift the frequency of incident light according to the Doppler principle. A color-coded image is generated representing blood flow distribution, which is analyzed to calculate the average perfusion over the area of interest, here the flap. To account for variables, such as ambient light and temperature, calculated perfusion was expressed as a ratio of flap to dorsal skin outside the region of radiation and ischemia. The mice were placed on a heating plate to minimize temperature variation.

\section{Whole Mounts}

Macroscopic neovascularization was assessed by whole mount using an FVB transgenic mouse. Eight- to ten-week-old tie2/lacZ male mice were flapped, irradiated and measured against controls. After 7 and 14 days, the flaps were excised and fixed in paraformaldehyde. LacZ expression was detected by incubating the 
Fig. 2. Limited ischemia and IR upregulates serum SDF-1 and VEGF levels. a After creation of an ischemic flap and exposure to $5 \mathrm{~Gy}$ of radiation, serum protein was harvested and analyzed for SDF-1 expression at progressive time points. A rise in serum SDF-1 is seen by $24 \mathrm{~h}$ and persists over 7 days, before returning to baseline. b Serum VEGF similarly increases by $24 \mathrm{~h}$, persisting to 4 days. ${ }^{*} \mathrm{p}<0.05$ comparing treated vs. controls. Error bars represent $\mathrm{SD}, \mathrm{n}=3$ /group.

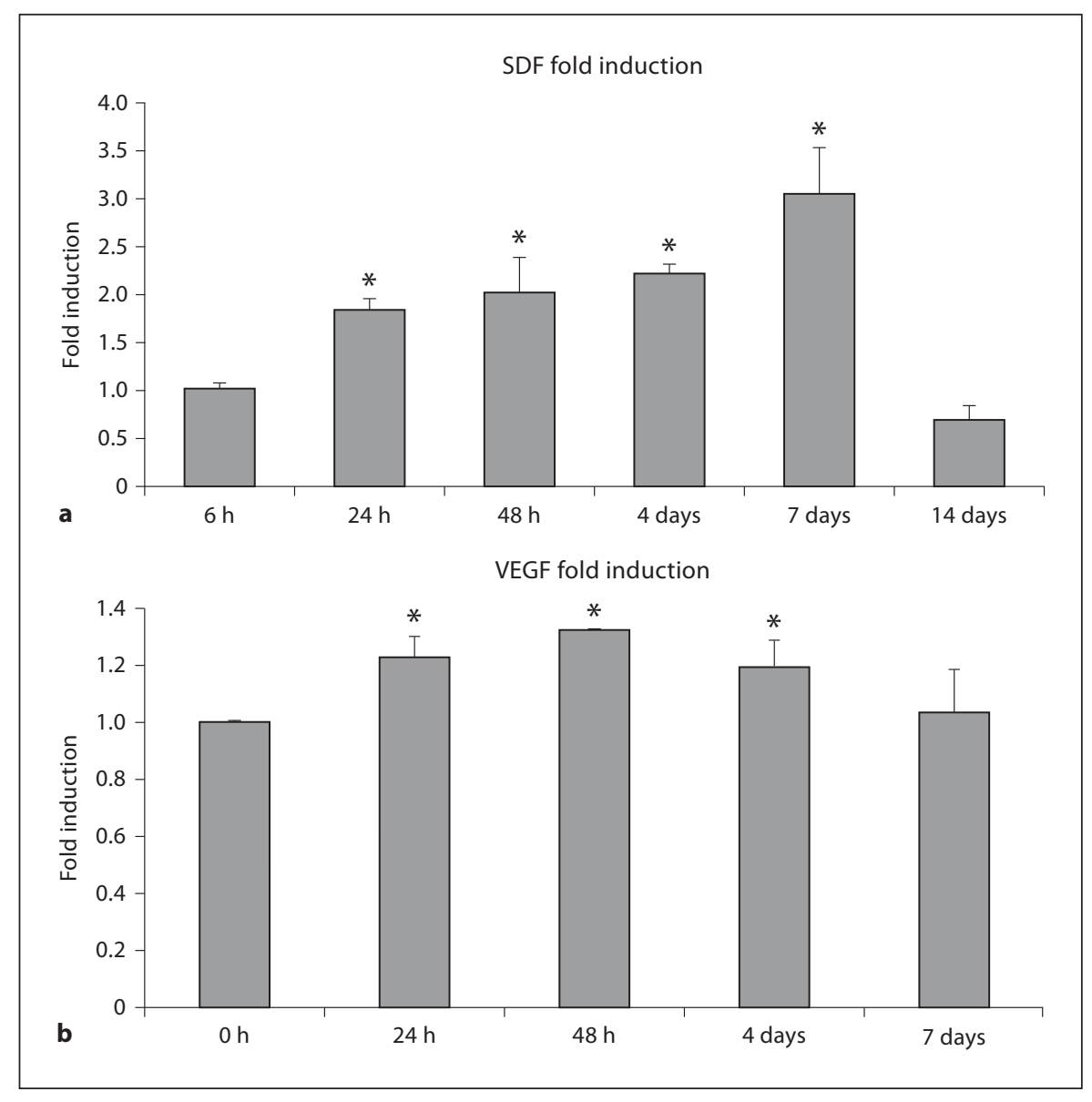

tissue with a $\beta$-galactosidase staining reagent (X-gal; Roche Labs). Stained whole-mount flaps were then placed on a standard light box to transilluminate the flaps, and photographs taken.

\section{Immunohistochemistry}

Skin flaps were harvested and placed into OCT tissue freezing medium or $10 \%$ formalin for paraffin embedding. Five-micrometer sections were cut and stained with hematoxylin and eosin or rat anti-mouse CD31 monoclonal antibody (BD Biosciences; Cat No. 550274). CD31 staining was quantified using Kodak 1D software.

\section{Peripheral Blood Collection}

Peripheral blood was collected into EDTA-treated tubes via clamshell thoracotomy and cardiac puncture. Mononuclear cells were isolated by gradient centrifugation (Histopaque 1077; Sig$\mathrm{ma}$ ) at $2250 \mathrm{RPM}$ for $30 \mathrm{~min}$ at $24^{\circ} \mathrm{C}$. Mononuclear cells were extracted and resuspended in a solution of PBS/2\% FBS/1\% EDTA for antibody staining. Serum was collected and frozen for serum cytokine analysis.

\section{Flow Cytometry}

Peripheral blood and bone marrow mononuclear cells were washed and stained with commercial rat anti-mouse antibodies (fluorescein isothiocyanate-conjugated Ly-6A/E, phycoerythrinconjugated VEFG-R2, allophycocyanin-conjugated CD117, biotin-conjugated lineage depletion cocktail, strepavidin-phycoerythrin-Cy7-conjugate antibodies; (BD Biosciences and Miltenyi Systems). All antibodies were titrated using serial dilutions and optimized for appropriate detection. At the time of analysis, cells were co-stained with 7-aminoactinomycin D (Invitrogen) in order to detect nonviable cells. Samples were collected using a Becton Dickinson FACSCaliber flow cytometer. Cytometric analysis was performed with FlowJo software, version 8.46 (TreeStar Inc.), as previously outlined [12].

\section{Serum ELISA}

MMP-9 and VEGF, SCF and SDF-1 protein levels were assessed by ELISA (R\&D Systems) utilizing the manufacturer's standard protocols. Serum samples (from density gradient centrifugation) were run in triplicate and standardized with a BCATM Protein Assay Kit (Pierce).

\section{Statistical Analysis}

Data are expressed as the mean $\pm \mathrm{SD}$. Data were analyzed with an unpaired two-tailed Student's t test or analysis of variance. Values of $\mathrm{p}<0.05$ were considered to be statistically significant. 
Fig. 3. Increased angiogenic factors are followed by upregulation of serum MMP-9 and s-kit. a Serum protein was harvested and analyzed for MMP-9 expression at progressive time points after flap creation and radiation. A rise in serum MMP-9 is seen at 4 days and persists over 14 days. b Serum s-kit similarly increases by 7 days, persisting to 14 days. ${ }^{*} \mathrm{p}<0.05$ comparing treated vs. controls. Error bars represent $\mathrm{SD}, \mathrm{n}=3$ /group.

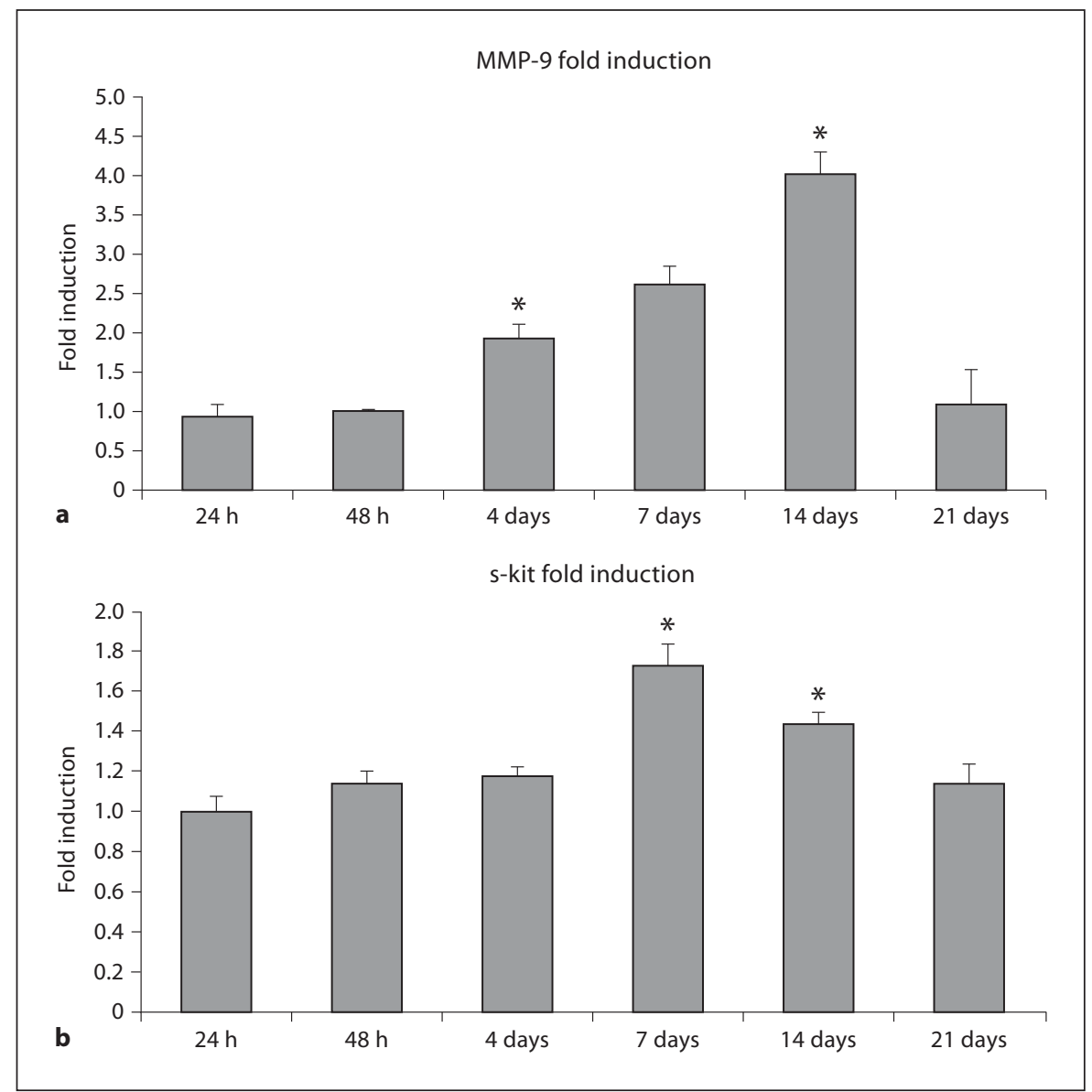

\section{Results}

\section{Localized Low-Dose Radiation Delivery to an}

Ischemic Flap Augments Systemic Elaboration of

Angiogenic Cytokines SDF-1 and VEGF

Ischemia has been shown to be a potent stimulus for the upregulation of angiogenic chemokines such as SDF1 and VEGF through HIF-1 pathways [13]. We have previously demonstrated that the presence of an ischemic full-thickness skin flap is a potent stimulus for this hypoxic response [4]. In order to examine the effect of IR on an ischemic flap, serum levels of SDF-1 and VEGF were examined following exposure with a single dose of 5 Gy radiation. Examination of serum protein levels by ELISA observed a robust increase in the levels of these chemokines in response to low-dose radiation compared to control mice undergoing flap alone. By $24 \mathrm{~h}$, serum SDF-1 levels had risen by 1.8 -fold in irradiated animals compared to controls, and peaked to 3.1-fold by day 7 (fig. 2a). Serum VEGF show a similar response with a 1.2-fold in- crease by $24 \mathrm{~h}$ and peaking at $48 \mathrm{~h}$ (fig. 2b). This in vivo finding is consistent with previous in vitro studies that demonstrate upregulation of VEGF and SDF-1 expression in response to IR through HIF-1-dependent and HIF-1-independent pathways [4]. Critically, increases in these chemokines are known to drive angiogenic and vasculogenic pathways.

\section{Localized Low-Dose Radiation Delivery to an \\ Ischemic Flap Upregulates Serum MMP-9 and s-kit \\ Levels}

We have demonstrated that radiation augments the release of angiogenic and vasculogenic chemokines on a systemic level. The process of vasculogenesis is dependent on the mobilization of progenitor cells from the bone marrow compartment into the systemic circulation, with subsequent homing to areas of ischemia. This mobilization of hematopoietic progenitor cells from the bone marrow compartment into the circulation is a complex process that has been demonstrated to be regulated 
through MMP-9/s-kit ligand-mediated pathways [14], with hypoxia, and direct upregulation by VEGF $[1,9]$, being one stimulus for induction. When we examine these signaling pathways, we see that low-dose radiation serves to further upregulate these factors. Serum MMP-9 levels are beginning to rise in the radiated groups at 4 days, with a peak 4 -fold rise at 14 days (fig. 3a). Serum s-kit levels rise as well over these time points (fig. $3 b$ ). These data suggest that elevations in the observed increases in serum SDF-1 and VEGF are correlating with increased MMP-9 and s-kit levels.

Progenitor Cell Mobilization Increases with the Addition of Low-Dose Radiation to an Ischemic Flap

Since our previous data demonstrated that the signaling pathways that regulate progenitor proliferation and mobilization are upregulated following low-dose radiation to an ischemic flap, we wanted to examine if the hematopoietic progenitor cells were mobilizing in the predicted manner. The Sca1+/Flk1+ mononuclear cell fraction was examined using flow-cytometric analysis of peripheral blood after treatment versus controls. Sca1+/ FLK1+ progenitors from irradiated mice were found to mobilize into the peripheral circulation by as much as 2 -fold compared to controls (fig. 4) at 10 days. This robust mobilization from the bone marrow compartment demonstrates that upregulation of vasculogenic pathways is occurring as a result of IR in the flap.

\section{Low-Dose Radiation Improves Perfusion to an \\ Ischemic Flap by Laser Doppler Analysis}

If the processes of angiogenesis and vasculogenesis are being augmented by low-dose radiation, there should be a resultant improvement in flap perfusion. To examine this, flap perfusion was analyzed with laser Doppler. The radiated flaps demonstrated significantly increased perfusion to the flap, with a 2 -fold increase in perfusion at the 14 day time point (fig. 5).

Fig. 4. Low-dose IR and cutaneous ischemia induce progenitor mobilization. Analysis of peripheral blood by flow cytometry identifies hematopoietic progenitor cells via Scal+/VEGFR2+ mononuclear cells in the control (a) and treated (b) animals. c Low-dose radiation to the ischemic flap has a systemic response, increasing progenitor cell mobilization by as much as 2 -fold compared to controls at the 10 day time point. $\mathrm{N}=3$ /group. ${ }^{*} \mathrm{p}<0.05$.
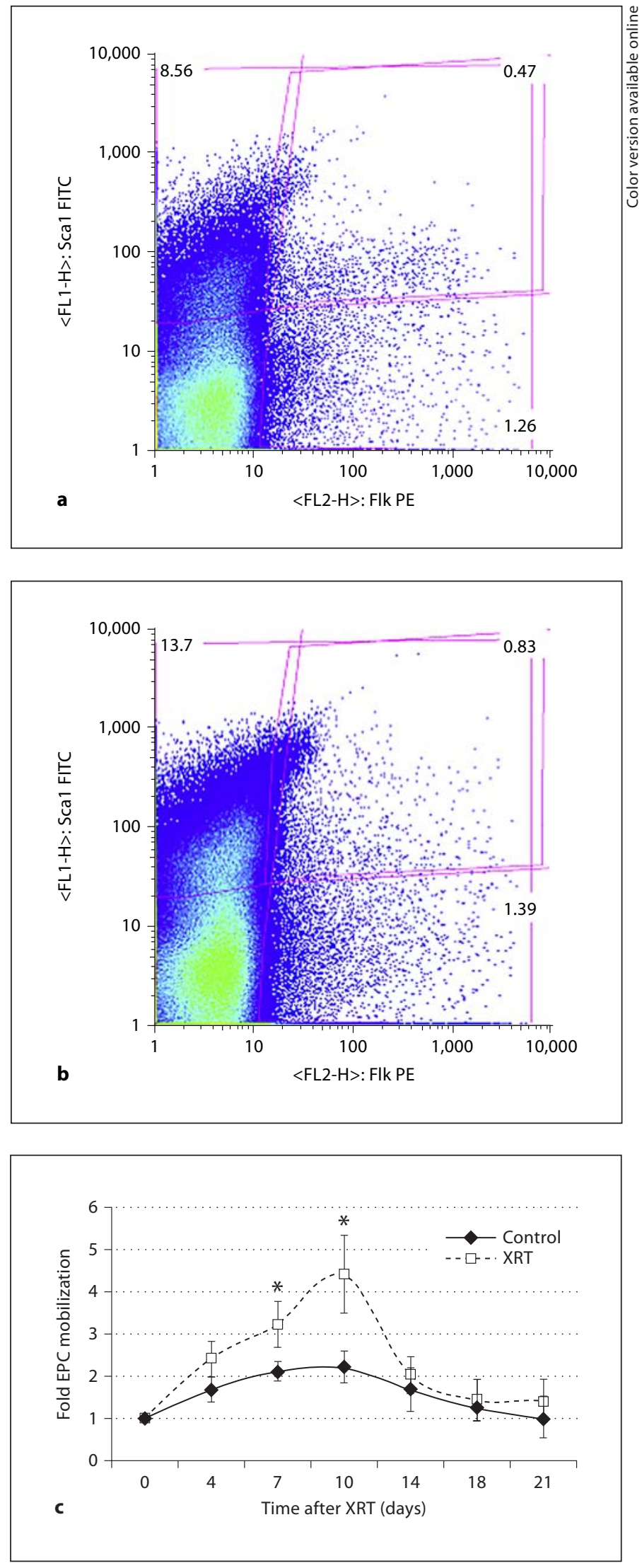


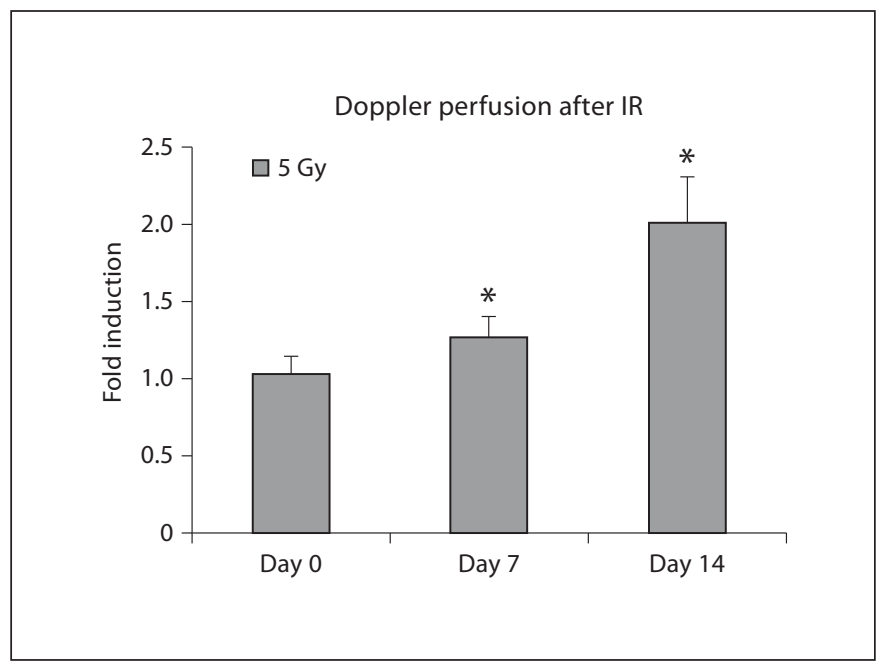

Fig. 5. Low-dose IR and cutaneous ischemia increase flap perfusion. Blood flow to the flap was measured by laser Doppler. Tissue irradiated at $5 \mathrm{~Gy}$ showed significantly increased blood flow to the distal flap compared with nonirradiated controls. ${ }^{*} \mathrm{p}<0.05 \mathrm{com}$ paring treated vs. controls, $n=3$ /group.

\section{Low-Dose Radiation Increases Neovascularization to an Ischemic Flap}

Increased perfusion to the flap can be a result of neovascularization, but could also occur by vasodilation of existing vessels. In order to evaluate the mechanism of increased perfusion, whole-mount analysis of the flaps was performed using tie $2 / \mathrm{LacZ}$ mice after B-galactosidase staining. Whole-mount analysis of the treated versus control flaps demonstrates clear neovascularization with increased blood vessel density and prominent vessel budding (fig. 6a). When these flaps are examined histologically by CD31 vessel counts, there is a significant increase in vascular density in the treated flaps versus controls (fig. 6b). Later time point analysis shows these changes to persist to 21 days.

\section{Discussion}

The ability to locally irradiate tissue and trigger a systemic response and improve neovascularization has vast therapeutic possibilities. In this study we have shown that localized, nonsystemic radiation can serve as this trigger. Using a well-described model of full-thickness cutaneous ischemia [10], we have shown that the addition of IR potentiates angiogenic and vasculogenic cytokine activity.

Cutaneous Radiation Increases Tissue Vascularity
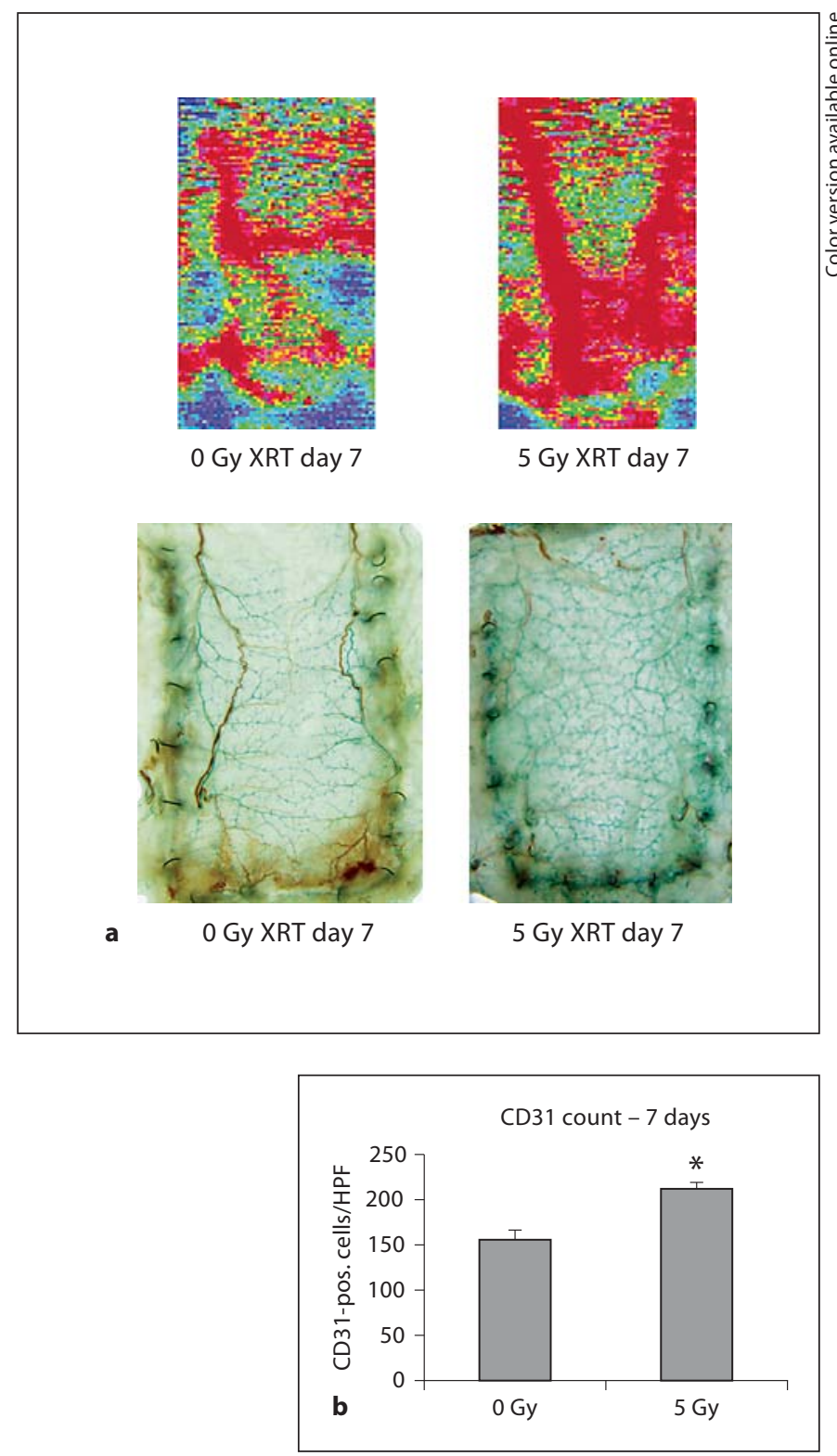

Fig. 6. Flap vascularity is increased after IR. a Top panel: laser Doppler analysis reveals increased perfusion in the irradiated flaps vs. controls. Lower panel: staining of transgenic tie $2 / \mathrm{LacZ}$ mice shows increased neovascular arborization and increased tie 2 gene expression in ischemic tissue 7 days after 5 Gy XRT. b Flaps were analyzed via immunohistochemical staining for CD31, a vascular endothelial marker. Tissue exposed to XRT showed significantly greater expression of CD $31 .{ }^{*} \mathrm{p}<0.05$. Error bars indicate $\mathrm{SD}, \mathrm{n}=3$ /group.

Neovascularization after injury is a complex series of events with contributions that occur through both the angiogenic and vasculogenic pathways, generally with signaling directed through the HIF-1 axis. Previous in

J Vasc Res 2010;47:472-480 
Fig. 7. Ischemia and ionizing radiation act synergistically to improve vascularity. Tissue ischemia and IR induces upregulation of HIF-1, leading to increased angiogenic and vasculogenic pathways. IR also directly upregulates MMP-9, which mobilizes progenitor cells through s-kit release. These dual factors ultimately improve tissue vascularity.

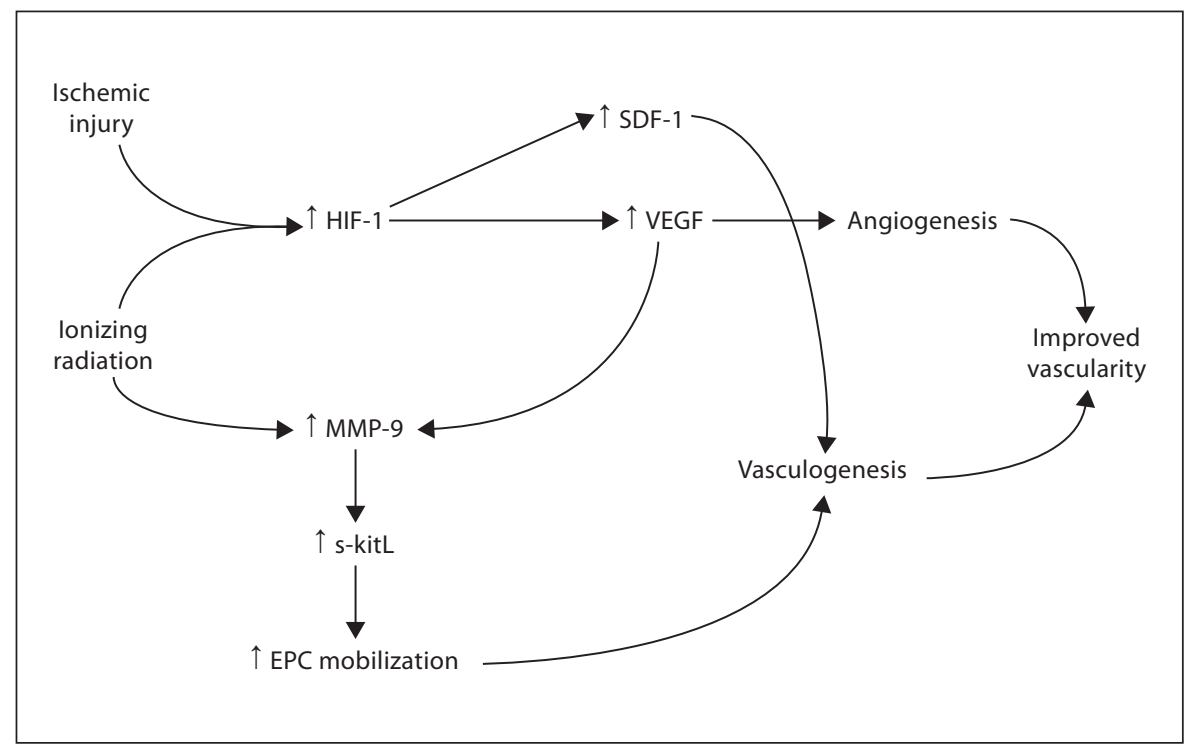

vitro studies have shown that IR can stimulate angiogenic signaling through HIF-1-dependent pathways [8, 15], and previous work in our lab shows that IR can upregulate vasculogenesis in an HIF-1-independent fashion as well. Here, we demonstrate that these effects are recapitulated in an in vivo system, with augmentation of systemic VEGF and SDF-1 levels in mice with irradiated ischemic flaps compared to control mice with ischemic flaps but no IR stimuli. In order to rule out IR causing increased flap ischemia, early time point laser Doppler analysis of the flaps was performed. Flaps exposed to IR show no increase in flap ischemia compared to controls. Furthermore, there was no increase in flap necrosis in irradiated flaps (data not shown). This suggests that the upregulation in these pro-angiogenic and pro-vasculogenic factors is caused by the direct induction of HIF-1 and HIF-1-independent factors by IR.

MMPs are endopeptidases whose role in angiogenesis was previously thought to be limited to degradation of the extracellular matrix to allow for migration of new cells involved in this process of revascularization [16]. It has become apparent recently that MMPs have a far greater role in angiogenesis and vasculogenesis. MMPs are involved in increasing the bioavailability of angiogenic chemokines and cytokines such as VEGF, and also cause release of s-kit, which promotes the mobilization of progenitor cells from the bone marrow compartment into the systemic circulation $[9,14,17]$. Our data demonstrates that the addition of localized radiation to a soft tissue flap alone creates a stimulus that upregulates se- rum MMP-9 levels with subsequent elevation of s-kit. This contributes to the growing body of evidence that MMPs play a critical role in neoangiogenesis that goes beyond matrix degradation, and that these effects can be potentiated by IR.

The process by which proliferating progenitor cells in the bone marrow niche mobilize to the circulation is a complex interaction between multiple cytokines, predominantly SDF-1 and VEGF, which act in an MMP-9dependent fashion $[1,18,19]$. Increasing levels of MMP-9 and corollary increases in s-kit would be expected to increase the levels of circulating progenitors [18]. We have demonstrated that the addition of IR to an ischemic flap causes an increase in serum VEGF and SDF-1, as well as increases in MMP-9 and s-kit when compared to controls. To evaluate circulating progenitors, we examined the Sca1+/Flk1+ cell fraction, which are stem and endothelial cell markers that have been identified as hematopoietic progenitor cells, and likely EPCs [20-26]. The markers that identify these cells continue to evolve, as does the thinking regarding their relative contributions to postnatal vascularization. When we examined this fraction of circulating progenitor cells, we observed a robust increase in progenitor cells in response to IR. These data suggest that IR-dependent stimulation of angiogenic cytokines results in mobilizing progenitor cells likely in an MMP-9-dependent fashion (fig. 7).

Work done previously in our lab demonstrated that progenitor cell trafficking is regulated by HIF-1 induction of SDF-1 to areas of hypoxia [4]. We have demon- 
strated how SDF-1 levels are augmented with the addition of IR to a hypoxic flap, and that there are increased levels of circulating progenitor cells. To examine if these factors result in increased neovascularization in an irradiated flap, we looked at flap vascularity and perfusion. We observed a clear increase in vascularity by B-Gal wholemount studies, with clear vascular buds throughout the flap as compared with controls. When examined histologically by assessing CD31 counts, there is increased staining in the treated animals. To examine whether this increase in blood vessels corresponded to increased flap perfusion we utilized laser Doppler analysis. Laser Doppler shows increased flap perfusion in treated flaps compared with nonirradiated controls. This data demonstrates that the addition of IR to an ischemic flap augments the hypoxic response, resulting in neovascularization and improved perfusion. Further work will need to focus on the contributions of progenitor cells at the irradiated site, in order to evaluate their specific role in the neovascularization observed.

The ability to augment the host response to ischemic injury has vast clinical implications. While the negative effects of higher-dose radiation are well described, this data adds to a growing body of evidence from our laboratory and others that suggests that in lower doses, that ionizing radiation can have a more isolated pro-angiogenic response by activating HIF-1-mediated pathways, essentially mimicking hypoxic signaling. In this study, we have demonstrated that low-dose radiation augments the hypoxic response in an ischemic full-thickness cutaneous flap. Low-dose radiation causes upregulation of angiogenic and vasculogenic chemokines, increases progenitor cell mobilization from the bone marrow into the peripheral circulation, and ultimately leads to increased perfusion and vascularity in an ischemic flap.

\section{References}

-1 Hattori K, Dias S, Heissig B, Hackett NR, Lyden D, Tateno M, Hicklin DJ, Zhu Z, Witte L, Crystal RG, Moore MA, Rafii S: Vascular endothelial growth factor and angiopoietin-1 stimulate postnatal hematopoiesis by recruitment of vasculogenic and hematopoietic stem cells. J Exp Med 2001;193:10051014.

-2 Hattori K, Heissig B, Wu Y, Dias S, Tejada R, Ferris B, Hicklin DJ, Zhu Z, Bohlen P, Witte L, Hendrikx J, Hackett NR, Crystal RG, Moore MA, Werb Z, Lyden D, Rafii S: Placental growth factor reconstitutes hematopoiesis by recruiting VEGFR1(+) stem cells from bone-marrow microenvironment. Nat Med 2002;8:841-849.

>3 Luttun A, Tjwa M, Moons L, Wu Y, Angelillo-Scherrer A, Liao F, Nagy JA, Hooper A, Priller J, De Klerck B, Compernolle V, Daci E, Bohlen P, Dewerchin M, Herbert JM, Fava R, Matthys P, Carmeliet G, Collen D, Dvorak HF, Hicklin DJ, Carmeliet P: Revascularization of ischemic tissues by PLGF treatment, and inhibition of tumor angiogenesis, arthritis and atherosclerosis by anti-flt1. Nat Med 2002;8:831-840.

$\checkmark 4$ Ceradini DJ, Kulkarni AR, Callaghan MJ, Tepper OM, Bastidas N, Kleinman ME, Capla JM, Galiano RD, Levine JP, Gurtner GC: Progenitor cell trafficking is regulated by hypoxic gradients through HIF-1 induction of SDF-1. Nat Med 2004;10:858-864.
5 De Falco E, Porcelli D, Torella AR, Straino S, Iachininoto MG, Orlandi A, Truffa S, Biglioli P, Napolitano M, Capogrossi MC, Pesce M: SDF-1 involvement in endothelial phenotype and ischemia-induced recruitment of bone marrow progenitor cells. Blood 2004; 104:3472-3482.

-6 Jin DK, Shido K, Kopp H-G, Petit I, Shmelkov SV, Young LM, Hooper AT, Amano H, Avecilla ST, Heissig B, Hattori K, Zhang F, Hicklin DJ, Wu Y, Zhu Z, Dunn A, Salari H, Werb Z, Hackett NR, Crystal RG, Lyden D, Rafii S: Cytokine-mediated deployment of SDF-1 induces revascularization through recruitment of CXCR4+ hemangiocytes. Nat Med 2006;12:557-567.

7 Walter DH, Haendeler J, Reinhold J, Rochwalsky U, Seeger F, Honold J, Hoffmann J, Urbich C, Lehmann R, Arenzana-Seisdesdos F, Aicher A, Heeschen C, Fichtlscherer S, Zeiher AM, Dimmeler S: Impaired CXCR4 signaling contributes to the reduced neovascularization capacity of endothelial progenitor cells from patients with coronary artery disease. Circ Res 2005;97:1142-1151.

-8 Moeller BJ, Cao Y, Li CY, Dewhirst MW: Radiation activates HIF-1 to regulate vascular radiosensitivity in tumors: role of reoxygenation, free radicals, and stress granules. Cancer Cell 2004;5:429-441.

9 Heissig B, Rafii S, Akiyama H, Ohki Y, Sato Y, Rafael T, Zhu Z, Hicklin DJ, Okumura K, Ogawa H, Werb Z, Hattori K: Low-dose irradiation promotes tissue revascularization through VEGF release from mast cells and MMP-9-mediated progenitor cell mobilization. J Exp Med 2005;202:739-750.
10 Tepper OM, Galiano RD, Capla JM, Kalka C, Gagne PJ, Jacobowitz GR, Levine JP, Gurtner GC: Human endothelial progenitor cells from type II diabetics exhibit impaired proliferation, adhesion, and incorporation into vascular structures. Circulation 2002;106: 2781-2786.

$>11$ Couffinhal T, Silver M, Zheng LP, Kearney M, Witzenbichler B, Isner JM: Mouse model of angiogenesis. Am J Pathol 1998;152:16671679 .

12 Ceradini DJ, Yao D, Grogan RH, Callaghan MJ, Edelstein D, Brownlee M, Gurtner GC: Decreasing intracellular superoxide corrects defective ischemia-induced new vessel formation in diabetic mice. J Biol Chem 2008; 283:10930-10938.

$>13$ Hitchon C, Wong K, Ma G, Reed J, Lyttle D, El-Gabalawy H: Hypoxia-induced production of stromal cell-derived factor 1 (CXCL12) and vascular endothelial growth factor by synovial fibroblasts. Arthritis Rheum 2002;46:2587-2597.

14 Heissig B, Werb Z, Rafii S, Hattori K: Role of c-kit/kit ligand signaling in regulating vasculogenesis. Thromb Haemost 2003;90:570576 .

15 Moeller BJ, Dewhirst MW: Raising the bar: how HIF-1 helps determine tumor radiosensitivity. Cell Cycle 2004;3:1107-1110.

16 Nelson AR, Fingleton B, Rothenberg ML, Matrisian LM: Matrix metalloproteinases: biologic activity and clinical implications. J Clin Oncol 2000;18:1135-1149. 
- 17 Heissig B, Hattori K, Friedrich M, Rafii S, Werb Z: Angiogenesis: vascular remodeling of the extracellular matrix involves metalloproteinases. Curr Opin Hematol 2003;10: 136-141.

18 Heissig B, Hattori K, Dias S, Friedrich M, Ferris B, Hackett NR, Crystal RG, Besmer P, Lyden D, Moore MA, Werb Z, Rafii S: Recruitment of stem and progenitor cells from the bone marrow niche requires MMP-9 mediated release of kit-ligand. Cell 2002;109: 625-637.

19 Hattori K, Heissig B, Tashiro K, Honjo T, Tateno M, Shieh JH, Hackett NR, Quitoriano MS, Crystal RG, Rafii S, Moore MA: Plasma elevation of stromal cell-derived factor-1 induces mobilization of mature and immature hematopoietic progenitor and stem cells. Blood 2001;97:3354-3360.
20 Asahara T, Kawamoto A: Endothelial progenitor cells for postnatal vasculogenesis. Am J Physiol Cell Physiol 2004;287:C572579.

-21 Asahara T, Masuda H, Takahashi T, Kalka C, Pastore C, Silver M, Kearne M, Magner M, Isner JM: Bone marrow origin of endothelial progenitor cells responsible for postnatal vasculogenesis in physiological and pathological neovascularization. Circ Res 1999;85 221-228.
22 Asahara T, Murohara T, Sullivan A, Silver M, van der Zee R, Li T, Witzenbichler B, Schatteman G, Isner JM: Isolation of putative progenitor endothelial cells for angiogenesis. Science 1997;275:964-967.

23 Hristov M, Erl W, Weber PC: Endothelial progenitor cells: mobilization, differentiation, and homing. Arterioscler Thromb Vasc Biol 2003;23:1185-1189.

24 Ingram DA, Caplice NM, Yoder MC: Unresolved questions, changing definitions, and novel paradigms for defining endothelial progenitor cells. Blood 2005;106:1525-1531.

-25 Tian F, Liang PH, Li LY: Inhibition of endothelial progenitor cell differentiation by vegi. Blood 2009; 113:5352-5360.

26 Rafii S, Lyden D: Therapeutic stem and progenitor cell transplantation for organ vascularization and regeneration. Nat Med 2003;9: 702-712. 